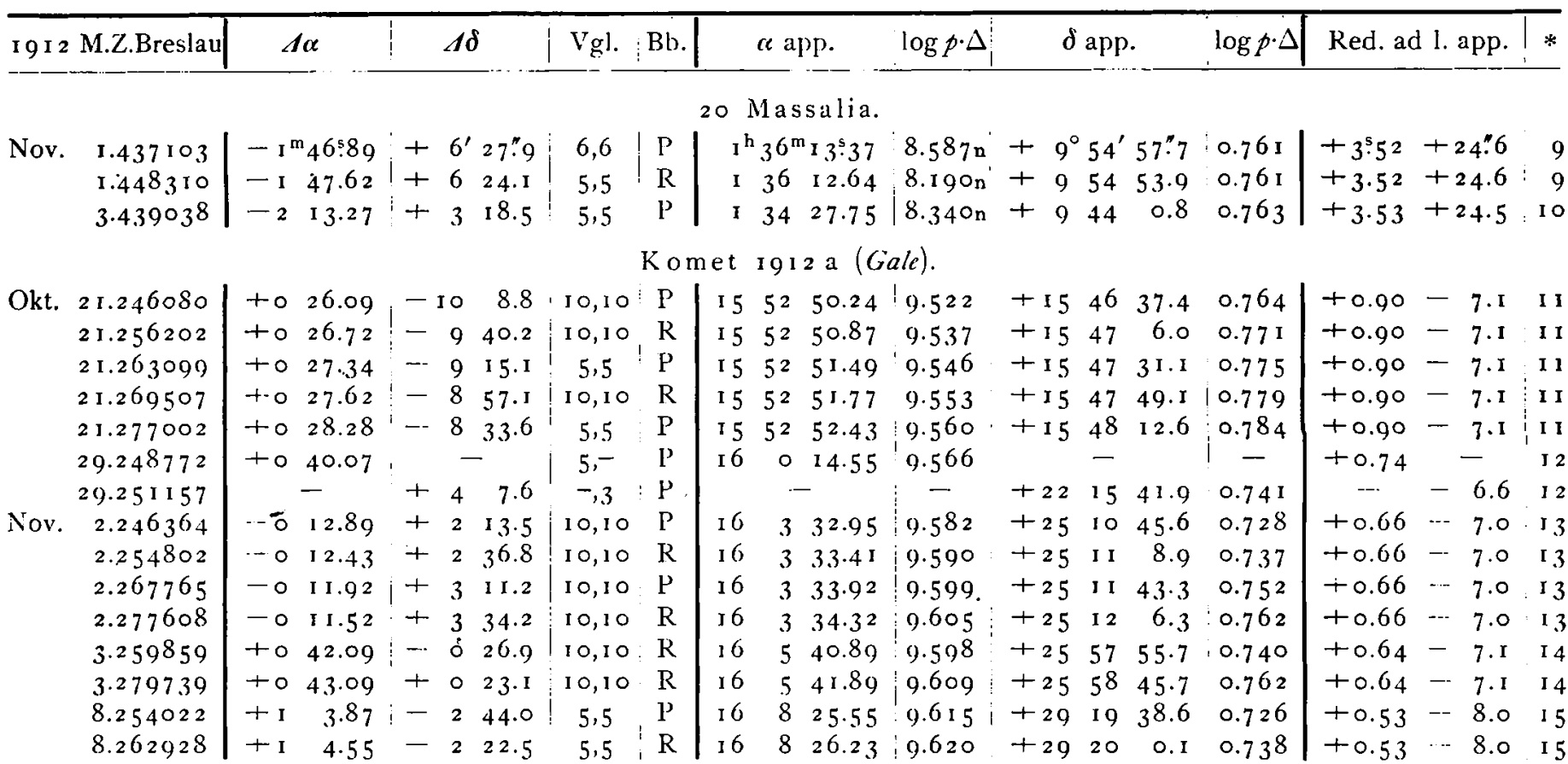

Mittlere Örter der Vergleichsterne.

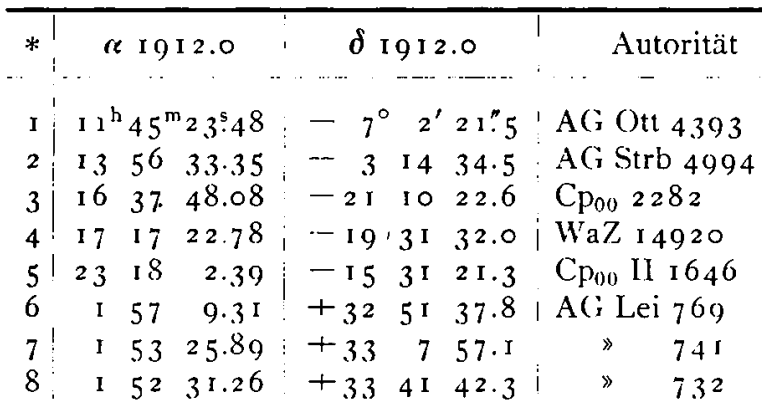

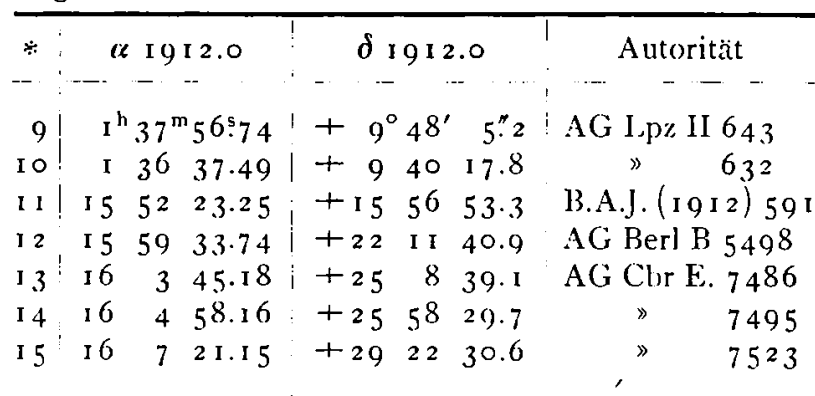

Die Beobachtungen wurden bei ruhendem Fernrohr angestellt, $\boldsymbol{A} \alpha$ mit dem Chronographen, $\boldsymbol{A} \delta$ mit der Mikrometerschraube gemessen. Nur die Anschlüsse von 324 Bamberga am 5. und 12. Oktober wurden durch Messung des Positionswinkels und der Distanz erhalten, da der Vergleichstern dem Planeten nahe genug stand. Vergrößerung $2 \mathbf{I} 5$, Okt. 5 5 Io. Okt. 13, 29 und Nov. 3 mußten die Beobachtungen wegen Bewölkung abgebrochen werden.

Komet Gale. Der Komet erschien immer rund, der Kern war meist deutlich wahrnehmbar. Fin Schweif ist nicht gesehen worden.

Breslau, I 9 I 2 Nov. 23.

F. I'avel.

\title{
Osservazioni di Pianeta 1913 QW.
}

1913 T.m. Roma C.R. $\Delta x \quad \Delta \delta \quad$ Cfr. Gr. $\quad \Delta \quad \alpha$ app. $\quad \log p \cdot \Delta \quad \delta$ app. $\quad \log p \cdot 1 \quad$ Red.adl.app. *

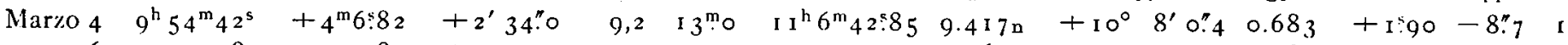

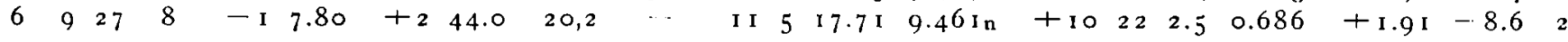

Stelle di confronto I9I3.0: I I I ${ }^{\mathrm{h}} 2^{\mathrm{m}} 34^{\mathrm{s}}: \mathrm{I} 3+10^{\circ} 5^{\prime} 35^{\prime \prime}$ I AG L.pz I 4 I 99 2 II $623.60+101927.1$ \$ 4222

Roma, Osservatorio al Collegio Romano, i 9 I 3 Marzo 7 .

F. Millosevich.

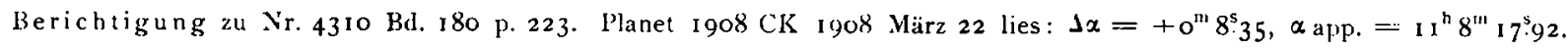

Inhalt zu Nr. 4637 . Ch. P. Olinier. $\propto$ Orionis. 8I. - D. Oubiago. Observations de l'éclipse de Soleil du i 7 Avril igiz. 83 . - Th. Ba. nachiewicz. Occultation prochaine de l'étoile $\mathrm{CP} T-22^{\circ} 7436$ par Jupiter. $87 .-7 . v$. - Bill. Beobachtungen des Borrelly schen Kometen I9II e. 89. - /. Naumann. Kometenbeobachtungen. 89. - F. Payel. Beobachtungen ain 203-mm Kefraktor der Breslauer Sternwarte. 93. - E. Hillosevich. Osservazioni di Pianeta 1913 (2W. 95. - Berichtigung. 95. 